\title{
OPEN The fate of methylmercury through the formation of bismethylmercury sulfide as an intermediate in mice
}

\author{
Yumi Abiko ${ }^{1}$, Yusuke Katayama ${ }^{2}$, Wenyang Zhao ${ }^{3,4}$, Sawako Horai ${ }^{5}$, Kenji Sakurai ${ }^{3,4}$ \& \\ Yoshito Kumagai ${ }^{1,2} \bowtie$
}

A previous study by our group indicated that methylmercury $(\mathrm{MeHg})$ is biotransformed to bismethylmercury sulfide $\left.\left[(\mathrm{MeHg})_{2} \mathrm{~S}\right)\right]$ by interaction with reactive sulfur species (RSS) produced in the body. In the present study, we explored the transformation of $\mathrm{MeHg}$ to $(\mathrm{MeHg})_{2} \mathrm{~S}$ in the gut and the subsequent fate of $(\mathrm{MeHg})_{2} \mathrm{~S}$ in vitro and in vivo. An ex vivo experiment suggested the possibility of the extracellular transformation of $\mathrm{MeHg}$ to $(\mathrm{MeHg})_{2} \mathrm{~S}$ in the distal colon, and accordingly, the $\mathrm{MeHg}$ sulfur adduct was detected in the intestinal contents and feces of mice administered $\mathrm{MeHg}$, suggesting that $(\mathrm{MeHg})_{2} \mathrm{~S}$ is formed through reactions between $\mathrm{MeHg}$ and $\mathrm{RSS}$ in the gut. In a cell-free system, we found that $(\mathrm{MeHg})_{2} \mathrm{~S}$ undergoes degradation in a time-dependent manner, resulting in the formation of mercury sulfide and dimethylmercury $(\mathrm{DMeHg})$, as determined by $\mathrm{X}$-ray diffraction and gas chromatography/mass spectrometry, respectively. We also identified DMeHg in the expiration after the intraperitoneal administration of $(\mathrm{MeHg})_{2} \mathrm{~S}$ to mice. Thus, our present study identified a new fate of $\mathrm{MeHg}$ through $(\mathrm{MeHg})_{2} \mathrm{~S}$ as an intermediate, which leads to conversion of volatile DMeHg in the body.

Mercury species are naturally occurring substances and industrially produced environmental contaminants, and their biogeochemical cycle is well known. For example, volatile mercury species, such as $\mathrm{Hg}^{0}$ or inorganic $\mathrm{Hg}^{2+}$, are deposited on soil and in water bodies by rainfall during volcanic activity. Inorganic mercury is methylated to yield methylmercury ( $\mathrm{MeHg}$ ) and then undergoes further methylation to form dimethylmercury (DMeHg) through nonenzymatic reactions and/or biotransformations in microbes ${ }^{1}$. MeHg in the environment can accumulate in fishes, such as tuna (Thunnus), and other marine creatures ${ }^{1,2}$. Humans are mainly exposed to $\mathrm{MeHg}$ through the intake of contaminated foods that are health risks. Due to the electrophilic nature of $\mathrm{MeHg}$, this organomercury compound covalently modifies protein thiols, thus leading to the formation of MeHg-protein adducts, which change protein functions ${ }^{3,4}$. We previously found that a lower MeHg dose modifies Kelch-like $\mathrm{ECH}$-associated protein 1 (Keap1) and phosphatase and tensin homolog deleted on chromosome ten (PTEN), thus leading to the activation of the Keap1/nuclear factor E2 related factor 2 (Nrf2) pathway and PTEN/Akt signaling, which are related to detoxication of xenobiotics and cell survival, respectively, whereas MeHg at a high dose disrupts cellular homeostasis, resulting in cell death ${ }^{5,6}$. Unlike $\mathrm{MeHg}$, DMeHg has little electrophilicity for modifying protein thiols but shows high and delayed toxicity 7,8 .

After being incorporated into the body, $\mathrm{MeHg}$ is effectively absorbed from the gastrointestinal tract and distributed through blood to various organs. Some $\mathrm{MeHg}$ in tissues interacts with small molecular nucleophiles, such as glutathione (GSH) produced by glutamate-cysteine ligase (GCL), in the absence and presence of GSH $S$-transferase (GST), and these interactions are referred to as phase II reactions and result in the formation of GSH adducts, which are excreted into the extracellular space through multidrug resistance-associated protein (MRP) in phase III reactions 9 . The series of reactions regulated by Nrf2 are considered a strategy to remove

\footnotetext{
${ }^{1}$ Faculty of Medicine, University of Tsukuba, 1-1-1 Tennodai, Tsukuba, Ibaraki 305-8575, Japan. ${ }^{2}$ Master's Program in Medical Sciences, Graduate School of Comprehensive Human Sciences, University of Tsukuba, Tsukuba, Ibaraki 305-8575, Japan. ${ }^{3}$ Doctoral Program in Materials Science and Engineering, Graduate School of Pure and Applied Sciences, University of Tsukuba, Tsukuba, Ibaraki 305-0006, Japan. ${ }^{4}$ National Institute for Materials Science, Tsukuba, Ibaraki 305-0047, Japan. ${ }^{5}$ Environmental Health Section, Department Environment and Public Health, National Institute for Minamata Disease, Minamata, Kumamoto 867-0008, Japan. ${ }^{\bowtie}$ email: yk-em-tu@ md.tsukuba.ac.jp
} 


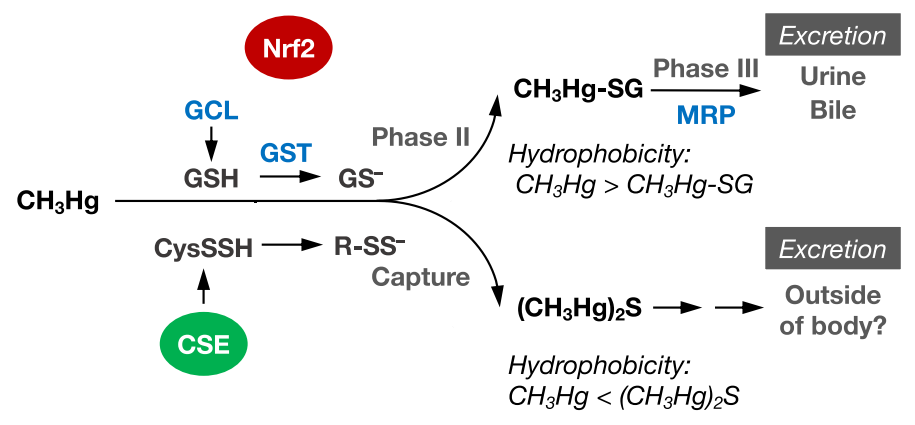

Figure 1. Biotransformation of methylmercury in the body. CSE cystathionine $\gamma$-lyase, CySSH cysteine persulfide, GCL glutamate-cysteine ligase, GSH glutathione, GS ${ }^{-}$deprotonated form of GSH, GST GSH $S$-transferase, $\mathrm{CH}_{3} \mathrm{Hg}$-SG methylmercury GSH adduct, $M R P$ multidrug resistance associated protein.

hydrophobic MeHg from cells (tissues) by conversion to a more hydrophilic GSH adduct (Fig. 1) because this transcription factor cooperatively regulates the gene expression of GCL, GST and MRP ${ }^{10,11}$. Although this polar GSH conjugates a detoxified metabolite ${ }^{9,12}$, the $\mathrm{Hg}-\mathrm{S}$ bond on the $\mathrm{MeHg}-\mathrm{SG}$ adduct is unstable ${ }^{13,14}$. Supporting this, our study suggested that MeHg-SG adduct undergoes $S$-transmercuration with reactive CysSH residues on proteins, resulting in formation of protein- $\mathrm{MeHg}$ adducts ${ }^{15}$, which are associated with the activation of redox signaling pathways and toxicity ${ }^{3,4}$, as mentioned above. Moreover, we previously identified bismethylmercury sulfide [methyl(methylmercuriosulfanyl)mercury; $(\mathrm{MeHg})_{2} \mathrm{~S}$ ] as a metabolite of $\mathrm{MeHg}$ from the liver of rats given $\mathrm{MeHg}$ and neuroblastoma SH-SY5Y cells exposed to $\mathrm{MeHg}^{16}$. Subsequent examination indicated that $(\mathrm{MeHg})_{2} \mathrm{~S}$ is formed by the interaction of $\mathrm{MeHg}$ with reactive sulfur species (RSS), which exhibit high nucleophilicity ${ }^{17,18}$ and include compounds such as GSH persulfide (GSSH) and protein-bound persulfide derived from CysSH persulfide $(\mathrm{CysSSH})$ and hydrogen sulfide $\left(\mathrm{H}_{2} \mathrm{~S}\right)$ produced by transsulfuration or enzymatic activities, such as cystathionine $\gamma$-lyase (CSE) activity ${ }^{19}$ (see Fig. 1). Although gut microbiota can produce $\mathrm{H}_{2} \mathrm{~S}$ under anaerobic and aerobic conditions ${ }^{20-22}$, the transformation of $\mathrm{MeHg}$ to $(\mathrm{MeHg})_{2} \mathrm{~S}$ in gut is unknown. Unlike the $\mathrm{MeHg}-\mathrm{SG}$ adduct, $(\mathrm{MeHg})_{2} \mathrm{~S}$ cannot interact with protein thiols ${ }^{16}$, suggesting that this sulfur adduct no longer has the covalent binding capability involved in $\mathrm{MeHg}$ toxicity. Nevertheless, $(\mathrm{MeHg})_{2} \mathrm{~S}$ is more hydrophobic than the parent compound MeHg. Therefore, we hypothesized that a system is responsible for excreting the sulfur adduct of $\mathrm{MeHg}$ outside the body. In the present study, we explored (1) the biotransformation of $\mathrm{MeHg}$ to $(\mathrm{MeHg})_{2} \mathrm{~S}$ in the gut and (2) the fate of $(\mathrm{MeHg})_{2} \mathrm{~S}$ in vitro and in vivo.

\section{Results}

Ex vivo and in vivo studies on the biotransformation of $\mathrm{MeHg}$. First, we determined whether $\mathrm{MeHg}$ reacted with RSS in intestinal lumen to form $(\mathrm{MeHg})_{2} \mathrm{~S}$. $(\mathrm{MeHg})_{2} \mathrm{~S}$ was produced by the incubation of $\mathrm{MeHg}(200 \mu \mathrm{M})$ in the mouse distal colon (but not in the duodenum with the colon's natural content) for $30 \mathrm{~min}$ under aerobic conditions (Fig. 2A,B), and a peak containing $\mathrm{Hg}$ with a retention time of 10-14 min was observed by high-performance liquid chromatography (HPLC)/atomic absorption spectrophotometry (AAS) ${ }^{19}$. Although $(\mathrm{MeHg})_{2} \mathrm{~S}$ was not detected during incubation of $\mathrm{MeHg}$ when the distal colon was washed with saline (Fig. 2C), incubation of $\mathrm{MeHg}$ with even the content alone produced $(\mathrm{MeHg})_{2} \mathrm{~S}$ (Fig. 2D). We boiled the intestinal contents to determine the contribution of proteins in microbes to $(\mathrm{MeHg})_{2} \mathrm{~S}$ formation and then reacted them with $\mathrm{MeHg}$. As a result, $(\mathrm{MeHg})_{2} \mathrm{~S}$ formation in the reaction mixture with boiled contents was decreased to $30 \%$ of the control (Fig. 2E). Correspondingly, using the supernatant of intestinal contents after removing the highmolecular-weight fraction significantly decreased the formation of $(\mathrm{MeHg})_{2} \mathrm{~S}$ from $\mathrm{MeHg}$ compared with using the whole supernatant (Fig. 2F). Moreover, significant differences in ( $\mathrm{MeHg})_{2} \mathrm{~S}$ production were not observed when the intestinal content and $\mathrm{MeHg}$ were incubated under aerobic or anaerobic conditions (Fig. 2G).

$\mathrm{MeHg}(10 \mathrm{mg} / \mathrm{kg})$ was orally injected into mice, and $(\mathrm{MeHg})_{2} \mathrm{~S}$ formation in the gut was analyzed. As shown in Fig. $2 \mathrm{H}-\mathrm{J},(\mathrm{MeHg})_{2} \mathrm{~S}$ was detected in the distal colon content and fecal sample but not in the duodenum content. These results suggest that fecal excretion of $(\mathrm{MeHg})_{2} \mathrm{~S}$ is, at least partially, attributable to the formation of $(\mathrm{MeHg})_{2} \mathrm{~S}$ from $\mathrm{MeHg}$ by RSS produced by the distal colon microbiota. Such a formation of $(\mathrm{MeHg})_{2} \mathrm{~S}$ from $\mathrm{MeHg}$ was also seen in the rectal content of another mammal, the small Indian mongoose (Supplemental Fig. S1).

Product analysis during degradation of $(\mathrm{MeHg})_{2} \mathrm{~S}$. We tested the stability of $(\mathrm{MeHg})_{2} \mathrm{~S}$ at $25^{\circ} \mathrm{C}$ in $50 \mathrm{mM}$ potassium phosphate buffer (KPi, pH 7.5) for 7 days. $(\mathrm{MeHg})_{2} \mathrm{~S}$ in the sample, as detected by HPLC/ AAS, was gradually degraded to $17.8 \%$ of the starting material, while $\mathrm{MeHg}$ was fairly stable under these conditions (Supplemental Fig. S2). We separated organic Hg species from the solution by liquid-liquid extraction with benzene and water to confirm the decomposition of $(\mathrm{MeHg})_{2} \mathrm{~S}$ and found that the $\mathrm{Hg}$ level in the benzene layer after 7 days was decreased to approximately $45.2 \%$ of the value at day 0 , while the $\mathrm{Hg}$ level in the water layer increased in a time-dependent manner (Fig. $3 \mathrm{~A})$. In a separate experiment, $(\mathrm{MeHg})_{2} \mathrm{~S}$ was also incubated with mouse liver supernatant centrifuged at $9000 \mathrm{~g}$. Although $72.2 \%$ of $(\mathrm{MeHg})_{2} \mathrm{~S}$ in $50 \mathrm{mM} \mathrm{KPi}$ buffer remained after one day, $(\mathrm{MeHg})_{2} \mathrm{~S}$ in the $9000 \mathrm{~g}$ supernatant markedly declined to $20.8 \%$ (Fig. 3B). Under this condition, heat treatment at $95^{\circ} \mathrm{C}$ and the removal of the high-molecular-weight fraction of the $9000 \mathrm{~g}$ supernatant significantly 


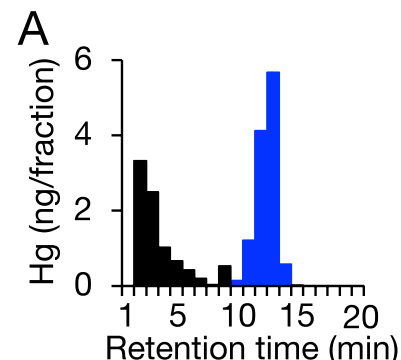

Retention time (min)
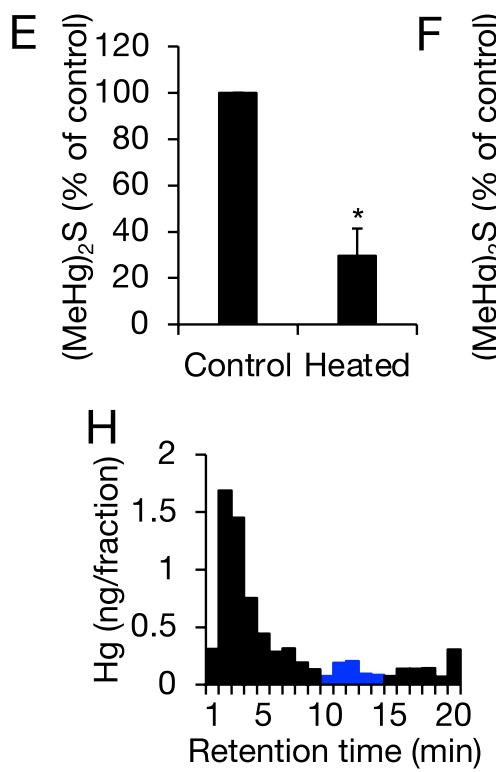
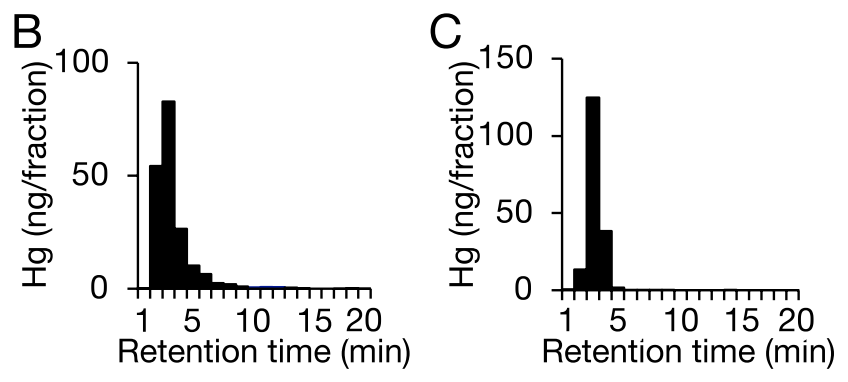
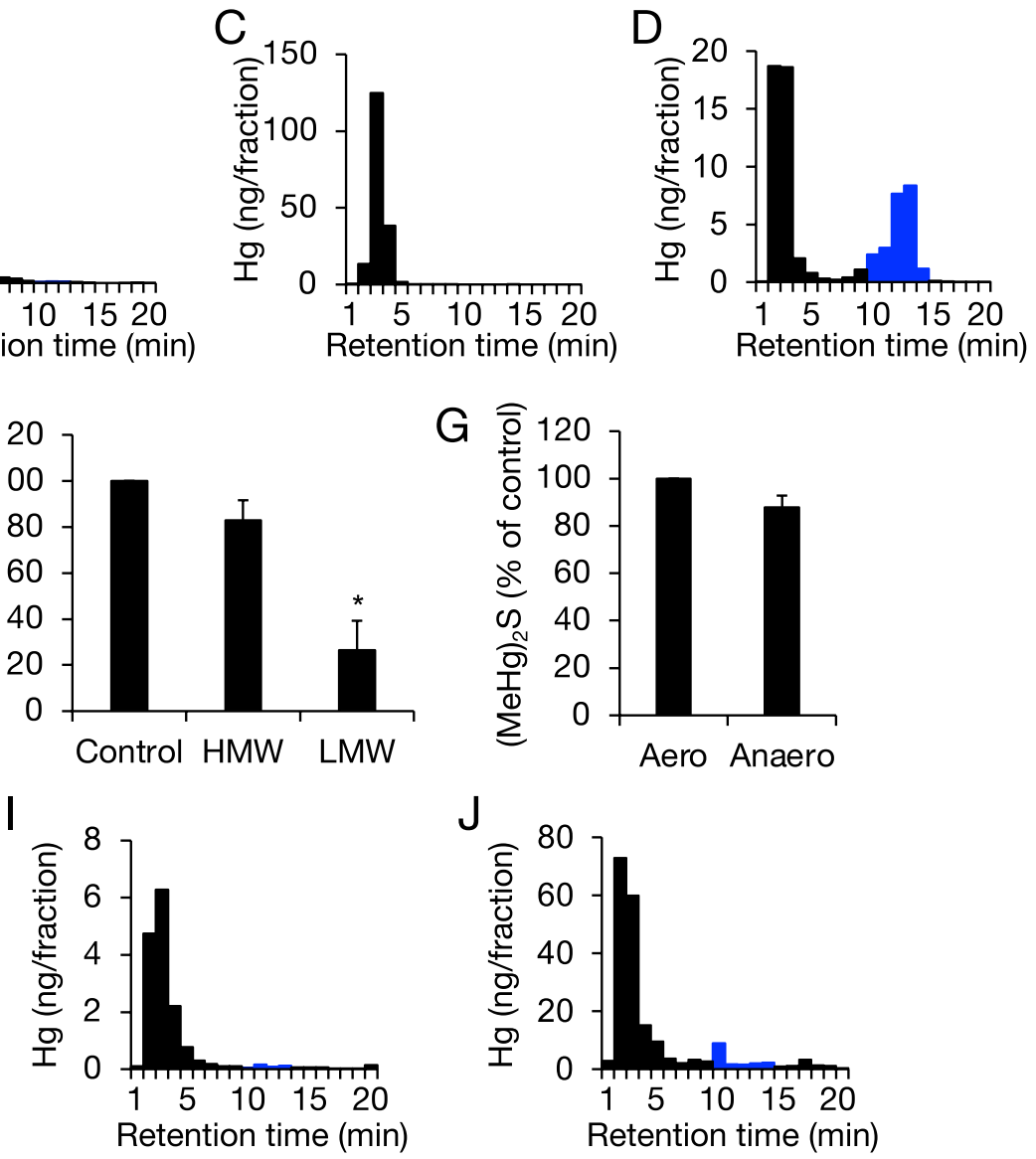

Figure 2. Detection of bismethylmercury sulfide as a reaction product of methylmercury with intestinal content in vitro and in vivo. Blue bars indicate $(\mathrm{MeHg})_{2} \mathrm{~S}$. $\mathrm{MeHg}(200 \mu \mathrm{M})$ was incubated in mouse (A) distal colon or (B) duodenum with content, (C) distal colon without content, or (D) $10 \mathrm{mg}$ of the content for $30 \mathrm{~min}$. (E) $\mathrm{MeHg}(200 \mu \mathrm{M})$ was incubated with $10 \mathrm{mg}$ of the content, which was preincubated at $25^{\circ} \mathrm{C}$ (control) or $95^{\circ} \mathrm{C}$ (heated) for $15 \mathrm{~min}$, for $30 \mathrm{~min}$. Each value of $(\mathrm{MeHg})_{2} \mathrm{~S}$ is the mean $\pm \mathrm{SE}$ of three determinations. ${ }^{\star} P<0.05$ vs. control. (F) MeHg $(200 \mu \mathrm{M})$ was incubated with $50 \mathrm{mg} / \mathrm{mL}$ homogenized content (control), its high-molecular-weight fraction (HMW), or its low-molecular-weight fraction (LMW) for $30 \mathrm{~min}$. The control sample was incubated in a tube under atmospheric air. Each value of $(\mathrm{MeHg})_{2} \mathrm{~S}$ is the mean $\pm \mathrm{SE}$ of three determinations. ${ }^{\star} P<0.05$ vs. control. (G) $\mathrm{MeHg}(200 \mu \mathrm{M})$ was incubated with homogenized intestine contents $(50 \mathrm{mg} / \mathrm{mL})$ for $30 \mathrm{~min}$ under anaerobic conditions (anaero). The control sample was incubated under atmospheric air (aero). Each value of $(\mathrm{MeHg})_{2} \mathrm{~S}$ is the mean $\pm \mathrm{SE}$ of three determinations. After $18 \mathrm{~h}$ of a single treatment with MeHg (10 mg/kg, p.o.), (H) the distal colon and (I) duodenum contents were collected. (J) The feces from mice given MeHg (10 mg/kg, p.o.) was collected after $18 \mathrm{~h}-42 \mathrm{~h}$ of exposure. The samples were analyzed by HPLC/AAS. Representative data are shown.

suppressed the degradation of $(\mathrm{MeHg})_{2} \mathrm{~S}$ compared to that with the nonheated supernatant (Fig. 3C), suggesting that heat-labile proteins participate in $(\mathrm{MeHg})_{2} \mathrm{~S}$ decomposition. Notably, the material balance of $\mathrm{Hg}$ levels was incomplete under these conditions (Fig. 3A), suggesting that unknown decomposition products seem to be volatile substances. To confirm this possibility, we collected unknown compounds from the head space of a sample tube containing $(\mathrm{MeHg})_{2} \mathrm{~S}$ by using XAD-4 resin for $3 \mathrm{~h}$. Gas chromatography/mass spectrometry (GC/MS) revealed that a product derived from $(\mathrm{MeHg})_{2} \mathrm{~S}$ with a retention time of $2.5 \mathrm{~min}$ had $\mathrm{m} / z=202\left({ }^{202} \mathrm{Hg}\right)(\mathrm{Fig}$. 3F), which is identical to that of authentic dimethylmercury (DMeHg) analyzed by GC/MS (Fig. 3D). In addition, the spectrum of the unknown product showing the parent ion $(\mathrm{m} / z=232)$ and the fragment ions $(\mathrm{m} / z=217,202$, and 15) (Fig. 3G) were almost the same as that of authentic DMeHg (Fig. 3F).

Moreover, we also collected black particles in the aqueous phase of the sample after incubation for 7 days, and the crystal structures were analyzed by X-ray diffraction (XRD). As shown in Fig. $3 \mathrm{H}$, the XRD pattern of the present black particles was nearly identical to that of authentic black $\beta$-HgS, which has a cubic structure (space group $F_{-} 43 \mathrm{~m}, \mathrm{a}=0.58537 \mathrm{~nm}$, ICDD PDF card 01-089-0432 $2^{23}$ ). The four strongest peaks were observed at $26.34^{\circ}, 43.72^{\circ}, 51.76^{\circ}$, and $30.52^{\circ}$ for $111,220,311$, and 200 reflections, respectively. A series of small peaks at $54.24^{\circ}, 63.60^{\circ}, 70.04^{\circ}, 72.10^{\circ}, 80.30^{\circ}, 86.32^{\circ}, 96.32^{\circ}, 102.26^{\circ}, 104.38^{\circ}$, and $112.80^{\circ}$ were observed for 222,400 , $331,420,422,511,440,531,442$, and 620 reflections, respectively ${ }^{23}$. Moreover, three or four small additional peaks were observed between $20^{\circ}$ and $30^{\circ}$ in the XRD patterns of the obtained black particles and authentic $\beta$-HgS (Fig. 3H,I). As discussed in Supplemental Fig. S3, all such XRD peaks were well explained by considering the second phase of $\alpha-\mathrm{HgS}$, which has a hexagonal structure (space group $P 3_{2} 21, \mathrm{a}=0.41495 \mathrm{~nm}, \mathrm{c}=0.9497 \mathrm{~nm}$, 

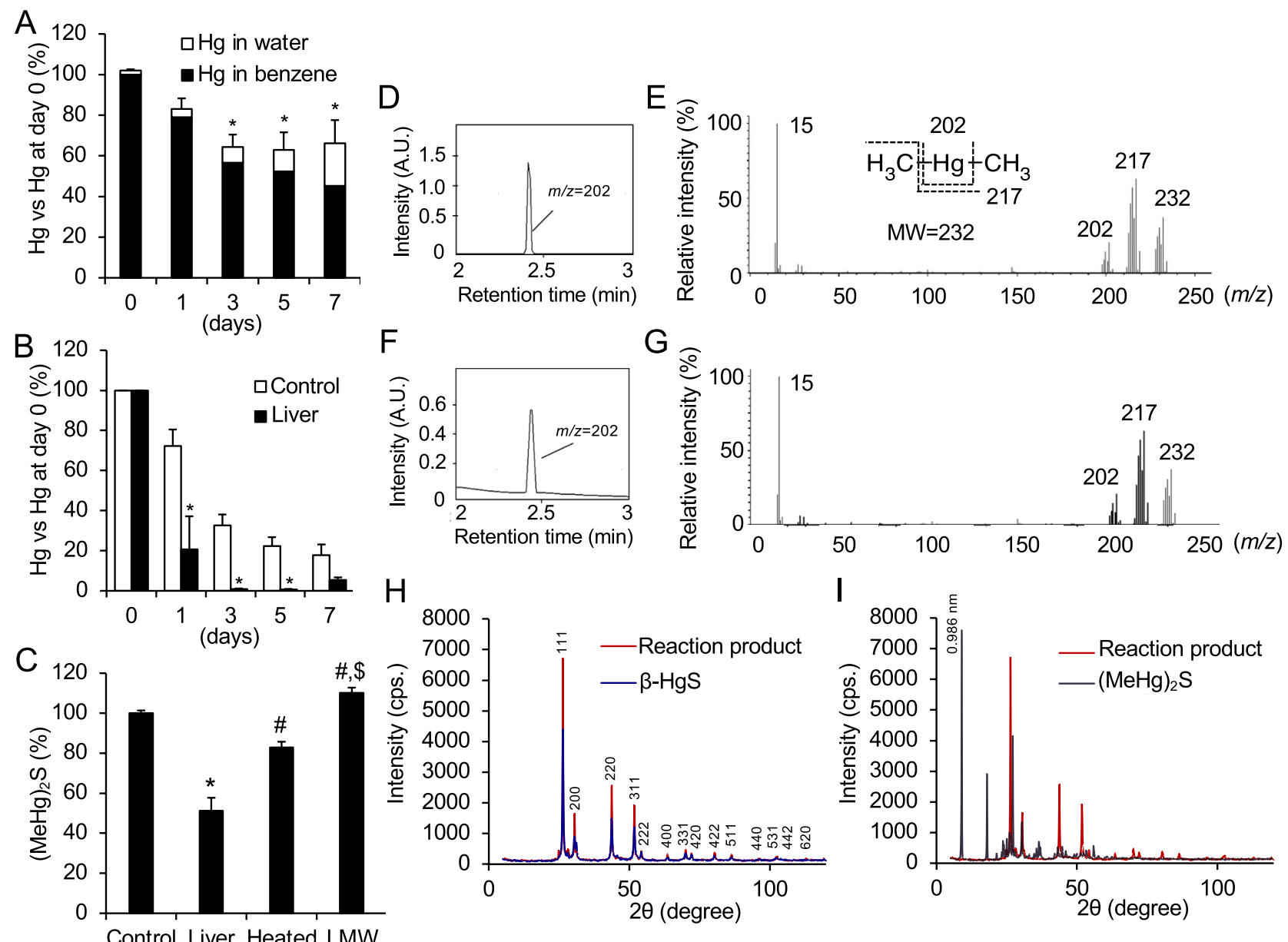

Control Liver Heated LMW

Figure 3. Detection of organic and inorganic mercury compounds during incubation with bismethylmercury sulfide. (A) $(\mathrm{MeHg})_{2} \mathrm{~S}$ was incubated for 0-7 days at $37^{\circ} \mathrm{C}$. After liquid-liquid extraction, the benzene layer and the water layer were separately analyzed by AAS. Each value is the mean $\pm \mathrm{SE}$ of three determinations. ${ }^{*} P<0.01$ vs. 0 day. (B) $(\mathrm{MeHg})_{2} \mathrm{~S}$ was incubated in mouse liver supernatant (liver) isolated by centrifugation at $9,000 \mathrm{~g}$ or in $50 \mathrm{mM} \mathrm{KPi} \mathrm{(pH} \mathrm{7.5)} \mathrm{(control)} \mathrm{for} 0-7$ days at $37^{\circ} \mathrm{C}$ and detected by HPLC/AAS. Each value is the mean $\pm \mathrm{SE}$ of three determinations. ${ }^{\star} P<0.01$ vs. 0 day. (C) Mouse liver $9000 \mathrm{~g}$ supernatant $(2 \mathrm{mg} / \mathrm{mL})$ was preincubated at $25^{\circ} \mathrm{C}$ or $95^{\circ} \mathrm{C}$. $(\mathrm{MeHg})_{2} \mathrm{~S}(100 \mu \mathrm{M})$ was incubated in $50 \mathrm{mM} \mathrm{KPi}(\mathrm{pH} 7.5)$ (control), supernatant (liver), heated supernatant (heated), or low-molecular-weight fraction of mouse liver $9000 \mathrm{~g}$ supernatant in $50 \mathrm{mM} \mathrm{KPi}(\mathrm{pH}$ 7.5) (LMW) for 1 day at $37^{\circ} \mathrm{C}$. $(\mathrm{MeHg})_{2} \mathrm{~S}$ was analyzed by HPLC-AAS. Each value is the mean $\pm \mathrm{SE}$ of three determinations. ${ }^{\star} P<0.001$ vs. control, ${ }^{\#} P<0.01$ vs. liver, ${ }^{\$} P<0.01$ vs. heated. The head space of a sample tube containing $(\mathrm{MeHg})_{2} \mathrm{~S}$ was collected and analyzed by GC/MS. (D) Chromatogram of authentic DMeHg and (E) spectrum of the peak with a retention time of $2.5 \mathrm{~min}$. (F) Chromatogram of the collected compounds and (G) spectrum of the peak with a retention time of $2.5 \mathrm{~min}$. The residue after 7 days of incubation with $(\mathrm{MeHg})_{2} \mathrm{~S}$ was purified. (H, I) Decomposition product (reaction product), $(\mathbf{H})$ authentic $\beta$-HgS, and $(\mathbf{I})(\mathrm{MeHg})_{2} \mathrm{~S}$ were analyzed by X-ray diffraction, and the patterns are shown.

ICDD PDF card 00-042-1408 $\left.{ }^{24}\right)$. In contrast, in Fig. 3I, the XRD pattern of the present black particles was clearly different from that of $(\mathrm{MeHg})_{2} \mathrm{~S}$ itself because the strongest peak from $(\mathrm{MeHg})_{2} \mathrm{~S}$ at $9.00^{\circ}$ (corresponding to $0.983 \mathrm{~nm}$ interplanar spacing) vanished completely. This finding clearly demonstrates that the original $(\mathrm{MeHg})_{2} \mathrm{~S}$ had decomposed and that an inorganic crystal of $\beta$-HgS was formed.

Detection of $\mathrm{CH}_{4}$ during decomposition of DMeHg in vitro. Because it is suggested that DMeHg is unstable under acidic conditions ${ }^{25,26}$, we incubated $\mathrm{DMeHg}$ or $\mathrm{MeHg}$ in $0.5 \mathrm{~N} \mathrm{HCl}$ solution and analyzed the decomposition products. A peak with a retention time of 1.79 min corresponding to methane $\left(\mathrm{CH}_{4}\right)(\mathrm{Fig}$. $4 \mathrm{~A}, \mathrm{~B})$ on GC/MS was detected in the head space of DMeHg at $3 \mathrm{~h}$ and 4 days of incubation (Fig. $4 \mathrm{C}-\mathrm{F}$ ), but not that of $\mathrm{MeHg}$ (Fig. 4G,H). This observation was consistent with previous findings ${ }^{26}$. Under the same conditions, a product with a similar electron ionization (EI)-MS fragmentation pattern as $\mathrm{MeHgCl}$ (Fig. 5A) was also observed in the $\mathrm{DMeHg}$ solution (Fig. 5B), and the peak containing $\mathrm{Hg}$ with the same retention time as authentic MeHg was detected by HPLC/AAS (Fig. 5C,D). We also analyzed DMeHg dissolved in methanol by EI-MS and observed $\mathrm{DMeHg}$; however, the $\mathrm{MeHg}$ level was negligible (Fig. 5E). These results suggest that $\mathrm{DMeHg}$ decomposed into $\mathrm{CH}_{4}$ and $\mathrm{MeHg}$ in aqueous solution. 

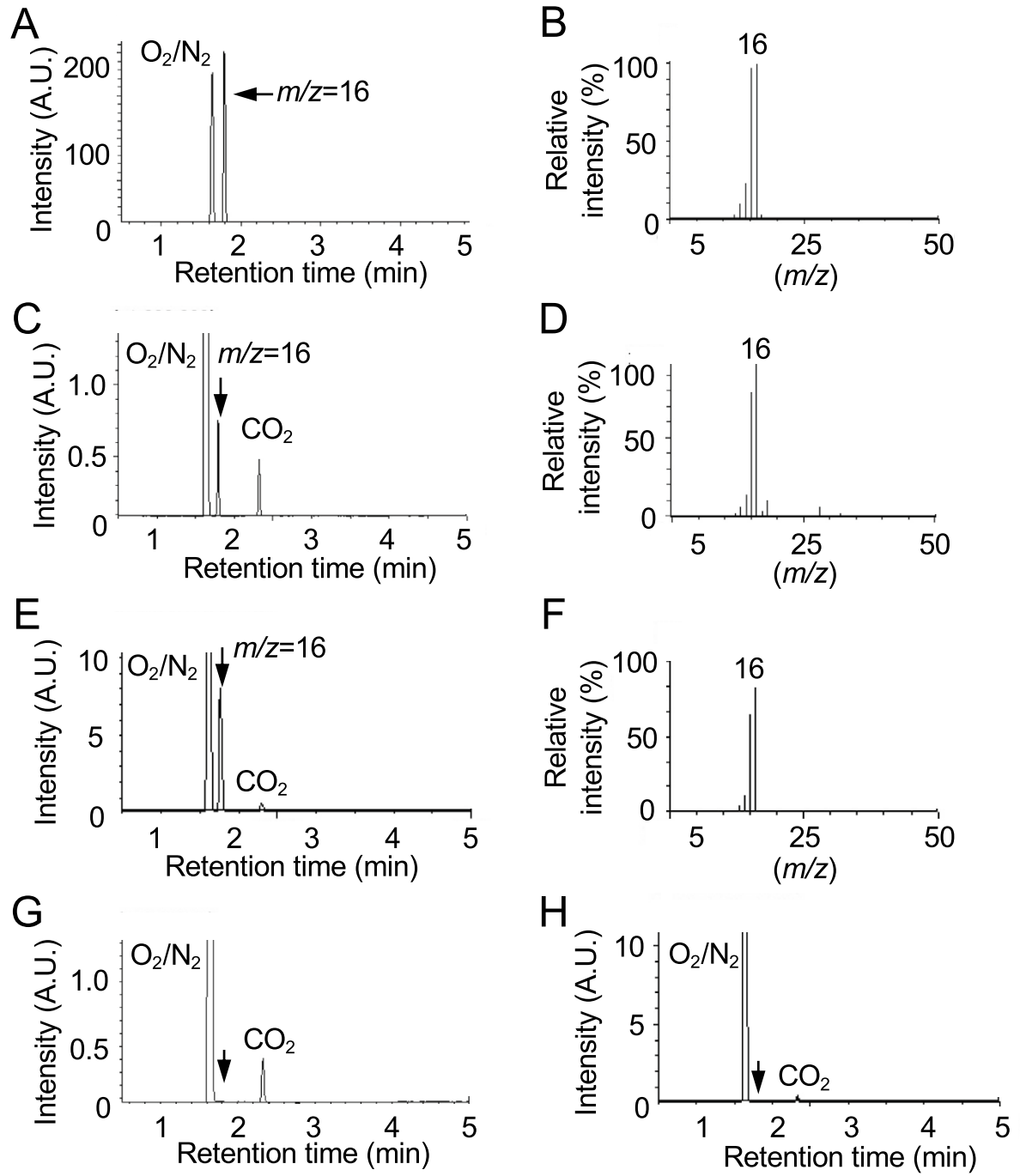

Figure 4. Detection of $\mathrm{CH}_{4}$ during dimethylmercury or methylmercury incubation by GC/MS analysis. The arrows indicate $\mathrm{CH}_{4}$. (A) Chromatogram of authentic $\mathrm{CH}_{4}$ and (B) spectrum of the peak with a retention time of 1.79 min. Compounds in the head space of DMeHg solution after (C, D) 3 h or (E, F) 4 days of incubation were analyzed by GC/MS. (C, E) Chromatogram of the collected compounds and (D, F) spectrum of the peak with retention time of $1.79 \mathrm{~min}$. Chromatogram of the collected compounds in the head space of MeHg solution after $(\mathbf{G}) 3 \mathrm{~h}$ or $(\mathbf{H}) 4$ days of incubation.

Identification of DMeHg from the exhaled breath of mice. Since DMeHg is a volatile material with a high vapor pressure $\left(8.8 \mathrm{kPa}\right.$ at $20^{\circ} \mathrm{C}$, reference from ICSC), we confirmed whether DMeHg derived from $(\mathrm{MeHg})_{2} \mathrm{~S}$ was distributed in the lung and then exhaled outside of the body. To address this issue, $\mathrm{DMeHg}$ $(0.1 \mathrm{mmol} / \mathrm{kg})$ was intraperitoneally injected into mice and then the exhaled air was collected for $3 \mathrm{~h}$. As shown in Fig. 6A,B, the collected sample showed a peak with a retention time of $2.5 \mathrm{~min}$ and an ion trace at $\mathrm{m} / z=202$ $\left({ }^{202} \mathrm{Hg}\right)$, and the spectrum pattern corresponded to authentic DMeHg (Figs. 3D,E, 6A,B). The samples collected $3 \mathrm{~h}$ after the intraperitoneal administration of $0.01 \mathrm{mmol} / \mathrm{kg}(\mathrm{MeHg})_{2} \mathrm{~S}$ or $\mathrm{MeHg}$ exhibited almost the same patterns as authentic DMeHg according to GC/MS (Fig. 6C,D, data not shown).

\section{Discussion}

In the present study, we identified DMeHg as a decomposition product of $(\mathrm{MeHg})_{2} \mathrm{~S}$ derived from $\mathrm{MeHg}$ in vitro and in vivo. Moreover, $\mathrm{HgS}$ was also formed during the decomposition of $(\mathrm{MeHg})_{2} \mathrm{~S}$. In nonbiological samples, Craig and Bartlett previously observed biphasic decay of $\mathrm{MeHg}$ in the presence of $\mathrm{H}_{2} \mathrm{~S}$ in an aqueous reaction mixture, with an initial rapid decay and then a slow decay that were probably due to the formation of $(\mathrm{MeHg})_{2} \mathrm{~S}$, which is a somewhat water-insoluble material, and evolution of DMeHg from the reaction mixture, respectively ${ }^{27}$, thus supporting the results of our cell-free study. We performed a series of experiments and suggested that $\mathrm{H}_{2} \mathrm{~S}$ generated in sediments may accelerate the transformation of $\mathrm{MeHg}$ to volatile $\mathrm{DMeHg}$, which moves to the atmosphere ${ }^{27-29}$. To our knowledge, previous reports have not focused on the biotransformation of $(\mathrm{MeHg})_{2} \mathrm{~S}$ to $\mathrm{DMeHg}$ in mammals. The present study indicates that $(\mathrm{MeHg})_{2} \mathrm{~S}$ biologically produced from 
A
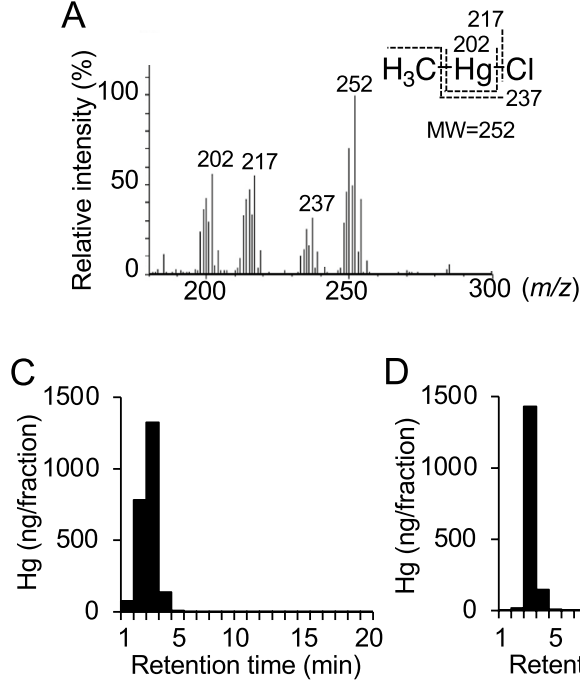

$\mathrm{B}$

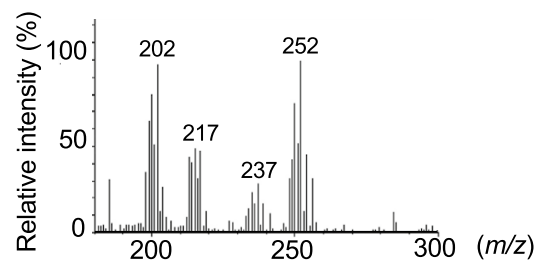

Figure 5. Detection of $\mathrm{MeHg}$ during incubation of dimethylmercury. $\mathrm{MeHg}$ or $\mathrm{DMeHg}$ were incubated in $0.5 \mathrm{~N} \mathrm{HCl}-50 \%$ methanol for 4 days. EI-MS spectra of (A) authentic $\mathrm{MeHgCl}$ and (B) DMeHg. Hg levels of (C) $\mathrm{MeHg}$ and (D) DMeHg solution were detected by HPLC/AAS analysis. (E) EI-MS spectrum of DMeHg in methanol.

$\mathrm{MeHg}$ is a key intermediate in the production of DMeHg, which is released from the lungs in mice (Figs. 6 and 7$)$. Such $(\mathrm{MeHg})_{2} \mathrm{~S}$ degradation was facilitated by the addition of the mouse liver supernatant centrifuged at $9000 \mathrm{~g}$, suggesting that unidentified high-molecular-weight components contribute, at least in part, to the decomposition of $(\mathrm{MeHg})_{2} \mathrm{~S}$.

We initially reported that $(\mathrm{MeHg})_{2} \mathrm{~S}$ was formed during interactions with RSS, such as $\mathrm{H}_{2} \mathrm{~S}$ produced by cystathionine $\beta$-synthase (CBS) in SH-SY5Y cells and in rats ${ }^{16}$. However, a subsequent study indicated that CBS and CSE catalyze the transformation of cystine to CysSSH, which interacts with GSH, thus forming GSSH and $\mathrm{H}_{2} \mathrm{~S}$ based on an equilibrium reaction among them ${ }^{17}$. In addition, we found that $(\mathrm{MeHg})_{2} \mathrm{~S}$ is formed with not only $\mathrm{H}_{2} \mathrm{~S}$ but also GSSH, GSSSG, protein-bound RSS and the synthetic polysulfide $\mathrm{Na}_{2} \mathrm{~S}_{4}$ during reaction with $\mathrm{MeHg}^{19}$. We have recently shown that phytochemical components in garlic contain RSS that form $(\mathrm{MeHg})_{2} \mathrm{~S}$ from $\mathrm{MeHg}^{30}$. Therefore, simultaneous intake of fish that accumulate $\mathrm{MeHg}$, such as tuna, with garlic would potentially lead to the increased formation of $(\mathrm{MeHg})_{2} \mathrm{~S}$ and concomitant production of DMeHg; as a result, the accumulation of $\mathrm{MeHg}$ in the body may be repressed by the intake of garlic. Further study is required to elucidate this possibility in vivo.

In addition to various enzymes (e.g., CBS and CSE) in organs, $\mathrm{H}_{2} \mathrm{~S}$ is produced by numerous gut microbes, such as Clostridium, Desulfovibrio, Escherichia, Klebsiella, Salmonella, Streptococcus, and Enterobacter ${ }^{20-22} \cdot \mathrm{H}_{2} \mathrm{~S}$ can react with oxidized thiol (sulfenic acid) compounds, including protein thiols, to yield persulfides, which have higher nucleophilicity than the corresponding monosulfides ${ }^{31}$. Although the gastrointestinal tract absorbs approximately $90 \%$ of $\mathrm{MeHg}^{32}$, we assumed that $\mathrm{MeHg}$ reacts with RSS to form $(\mathrm{MeHg})_{2} \mathrm{~S}$ derived from the bacterial system in the mouse intestine. Herein, we show for the first time that $(\mathrm{MeHg})_{2} \mathrm{~S}$ is produced in the mouse distal colon with its contents (Fig. 2). We also detected ( $\mathrm{MeHg})_{2} \mathrm{~S}$ in the distal colon content and in mouse feces following $\mathrm{MeHg}$ administration (Fig. 2H-J). Interestingly, the low-molecular-weight fraction of supernatant from the intestinal content produced less $(\mathrm{MeHg})_{2} \mathrm{~S}$ than the high-molecular-weight fraction or the whole supernatant. While the LC/MS analysis indicated that $\mathrm{H}_{2} \mathrm{~S}$ as well as $\mathrm{H}_{2} \mathrm{~S}_{2}$ were observed in the mouse feces and that a small amount of $\mathrm{H}_{2} \mathrm{~S}$ and $\mathrm{H}_{2} \mathrm{~S}_{2}$ were in the germ-free mice ${ }^{33}$, our present study suggested that not only low-molecular-weight RSS but also protein-bound RSS in the intestinal content facilitate $(\mathrm{MeHg})_{2} \mathrm{~S}$ production from $\mathrm{MeHg}$. Hence, it seems likely that the formation of $(\mathrm{MeHg})_{2} \mathrm{~S}$ in the distal colon content and substantial excretion of this sulfur adduct in mice are attributable to gut microbe-dependent RSS. In the present study, we also detected $(\mathrm{MeHg})_{2} \mathrm{~S}$ from the rectal content of the wild small Indian mongoose (Herpestes auropunctatus) (Supplemental Fig. S1), which has a relatively high level of total $\mathrm{Hg}$ in its tissues ${ }^{34}$ that did not undergo artificial exposure to $\mathrm{MeHg}$, suggesting that $(\mathrm{MeHg})_{2} \mathrm{~S}$ formation, at least in part, is due to a biotransformation mediated by gut microbe-dependent RSS in the mongoose.

We incubated DMeHg with $\mathrm{H}_{2} \mathrm{O}$ and found that $\mathrm{CH}_{4}$ and $\mathrm{MeHg}$ were formed from DMeHg under acidic conditions (Figs. 4 and 5), suggesting that sulfur adducts of $\mathrm{MeHg}$ are critical precursors for (1) excretion from the body through the formation of volatile $\mathrm{DMeHg}$ and (2) substantial preservation of these parent substances in the body by recycling $\mathrm{MeHg}$. In the present study, $\mathrm{HgS}$ was also identified by XRD during spontaneous degradation of $(\mathrm{MeHg})_{2} \mathrm{~S}$, suggesting that $\mathrm{HgS}$ is the counterpart for DMeHg, although we did not examine the exact stoichiometry of $(\mathrm{MeHg})_{2} \mathrm{~S}$ and that these products formed in the study. Since $\mathrm{HgS}$ is an insoluble nanoparticle, the simple question of how this particle is stored or excreted from the body should be addressed in the near future. 
A

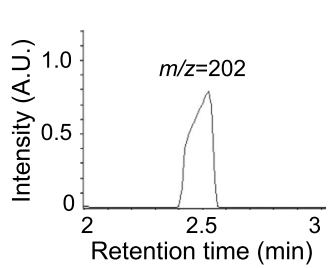

C

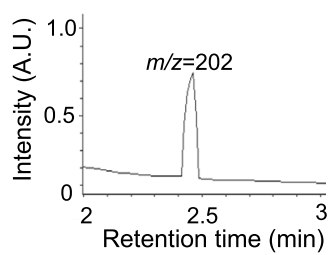

$\mathrm{B}$
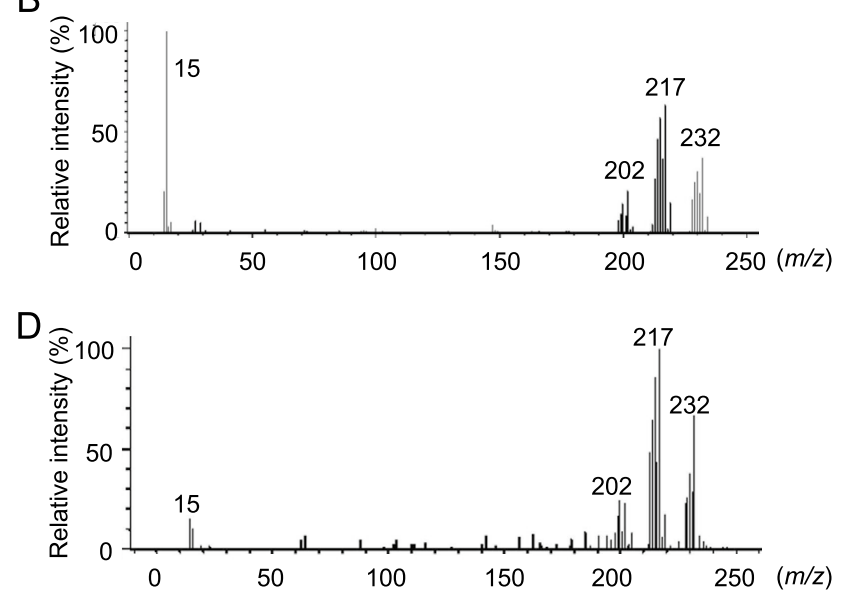

Figure 6. GC/MS analysis of mouse expirate after treatment with dimethylmercury or bismethylmercury sulfide. Chemicals in the exhaled air of mice given a single injection of $(\mathbf{A}, \mathbf{B}) 0.1 \mathrm{mmol} / \mathrm{kg} \mathrm{DMeHg}$ and $(\mathbf{C}, \mathbf{D})$ $(\mathrm{MeHg})_{2} \mathrm{~S}$ were analyzed by GC/MS. (A, C) Chromatogram of the collected compounds and (B, D) spectra of the peak with a retention time of $2.5 \mathrm{~min}$. Representative data are shown.

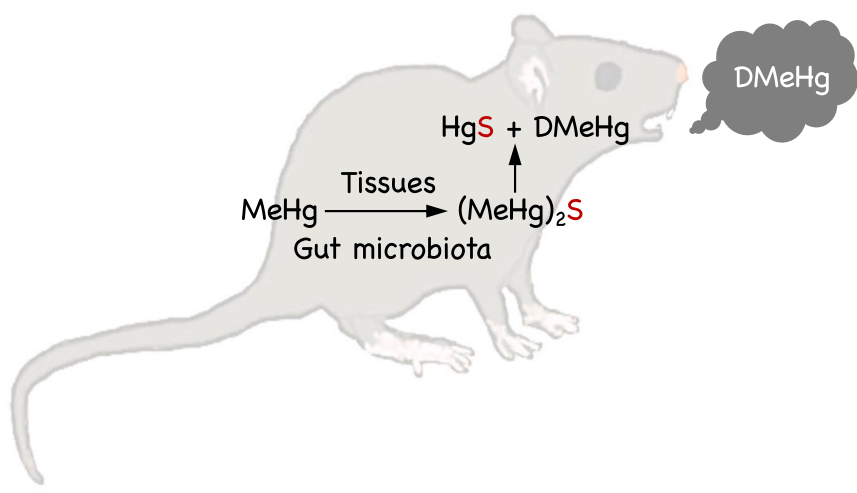

Figure 7. Excretion of dimethylmercury through the formation of bismethylmercury sulfide in mice. $\mathrm{DMeHg}$ dimethylmercury, $\mathrm{MeHg}$ methylmercury, $(\mathrm{MeHg})_{2} \mathrm{~S}$ bismethylmercury sulfide. $\mathrm{MeHg}$ was transformed into $(\mathrm{MeHg})_{2} \mathrm{~S}$ via reaction with reactive sulfur species in tissue and intestine. A portion of intestinal $(\mathrm{MeHg})_{2} \mathrm{~S}$ might be absorbed into the body. $(\mathrm{MeHg})_{2} \mathrm{~S}$ slowly decomposed to $\mathrm{HgS}$ and $\mathrm{DMeHg}$, which could be excreted from the body.

\section{Methods}

Materials and methods. $\mathrm{MeHgCl}$ (98\% purity) and $\mathrm{DMeHg}$ (95\% purity) were obtained from SigmaAldrich (St. Louis, MO, USA). Mercury standard solution, formic acid and methanol were obtained from Nacalai Tesque Inc. (Kyoto, Japan). $\mathrm{Na}_{2} \mathrm{~S}$ and XAD-4 were purchased from FUJIFILM Wako Pure Chemical Co. (Osaka, Japan) and ACROS Organics (Fair Lawn, NJ, USA), respectively. All other reagents used were of the highest purity available. $(\mathrm{MeHg})_{2} \mathrm{~S}$ was synthesized as previously described ${ }^{16}$.

Animal experiments. All protocols for animal experiments, which were carried out in compliance with the ARRIVE guidelines, were approved by the University of Tsukuba Animal Care and Use Committee and followed the committee's guidelines for alleviating suffering. C57BL/6 J 8-week-old female mice (Clea Japan, Tokyo, Japan) were fasted for $12 \mathrm{~h}$ before treatment with the compounds, and all experiments with exposure to chemicals were performed with a single administration.

After euthanasia, the intestines, intestinal contents and liver were removed for each experiment. The colon or duodenum was tied using a surgical suture before removal or washed with saline after removal. $\mathrm{MeHg}(200 \mu \mathrm{M}$ in saline-5\% methanol) was injected into the intestine, and then the intestine was covered by soaked Kimwipe with saline and incubated for $30 \mathrm{~min}$ at room temperature. The washed distal colon was incubated with $\mathrm{MeHg}$ (200 $\mu \mathrm{M}$ in saline-5\% methanol) for $30 \mathrm{~min}$ at room temperature. The distal colon content (10 mg) was incubated with $\mathrm{MeHg}(200 \mu \mathrm{M})$ for $30 \mathrm{~min}$ at $25^{\circ} \mathrm{C}$. After incubation, formic acid (at a final concentration of $1 \%$ ) 
was added to the mixture, which was then centrifuged at $14000 \mathrm{~g}$ for $5 \mathrm{~min}$. The supernatant was analyzed by HPLC/AAS as described below.

For the HPLC/AAS analysis of $(\mathrm{MeHg})_{2} \mathrm{~S}$ in intestinal contents or feces, mice were orally administered mercury compounds dissolved in saline. $(\mathrm{MeHg})_{2} \mathrm{~S}$ in the fecal samples from mice given $10 \mathrm{mg} / \mathrm{kg} \mathrm{MeHg}$ for $18-42 \mathrm{~h}$ was extracted by $50 \%$ methanol- $10 \%$ formic acid. After centrifugation $\left(13000 \mathrm{~g}, 4^{\circ} \mathrm{C}\right)$, the samples were analyzed by HPLC/AAS as described below.

To detect DMeHg in the expirate, $\mathrm{MeHgCl}, \mathrm{DMeHg}$, or $(\mathrm{MeHg})_{2} \mathrm{~S}(0.1 \mathrm{mmol} / \mathrm{kg})$ dissolved in corn oil was intraperitoneally injected into mice and then the expirate was aspirated by pumping $(50 \mathrm{~mL} / \mathrm{min})$ through a mask connected to an XAD-4 (500 mg) column for $3 \mathrm{~h}$. XAD-4 was set on both sides (air in/out) of the mask to avoid contamination with mercury species from the environment. Absorbed chemicals were extracted by $1 \mathrm{~mL}$ of acetone and analyzed by GC/MS (GCMS-QP2020, Shimadzu, Kyoto, Japan).

Sample preparation using the mouse intestine contents and liver for HPLC/AAS. To determine the contribution of gut microbiota to $(\mathrm{MeHg})_{2} \mathrm{~S}$ formation from $\mathrm{MeHg}$, the distal colon content was incubated at $25^{\circ} \mathrm{C}$ or $95^{\circ} \mathrm{C}$ for $15 \mathrm{~min}$ and then cooled on ice for $5 \mathrm{~min}$. The content $(10 \mathrm{mg})$ was incubated with $\mathrm{MeHg}$ [200 $\mu \mathrm{M}$ in phosphate-buffered saline (pH 7.5) (PBS)-5\% methanol] for $30 \mathrm{~min}$ at $25^{\circ} \mathrm{C}$, followed by addition of formic acid (at a final concentration of $1 \%)$. Distal colon content $(200 \mathrm{mg}$ ) from two mice for one experiment was homogenized in PBS $(1 \mathrm{~mL})$ and centrifuged at $9000 \mathrm{~g}$, the supernatant was collected, and then the lowmolecular-weight fraction of the supernatant was fractionated using Amicon Ultra (Ultracel $3 \mathrm{~K}$, Merck, Darmstadt, Germany) and the high-molecular-weight fraction was fractionated using a PD SpinTrap G-25 column (GE Healthcare, Buckinghamshire, UK). The reaction mixtures were centrifuged at $12000 \mathrm{~g}$ for $5 \mathrm{~min}$, and then the supernatant was analyzed by HPLC/AAS. An aliquot of homogenized distal colon content $(200 \mathrm{mg} / \mathrm{mL}) \mathrm{was}$ transferred into the principal chamber of a Thunberg tube, and PBS $(1.75 \mathrm{~mL})$ was added. Five hundred microliters of MeHg (1.2 mM in PBS-30\% methanol) was transferred into another side of the Thunberg tube. The tube was vacuumed by a pump for $3 \mathrm{~min}$ and then filled with argon gas. This step was repeated three times to achieve anerobic conditions. Samples were mixed in the tube and incubated at $37^{\circ} \mathrm{C}$ for $30 \mathrm{~min}$. The reaction mixtures were centrifuged at $12000 \mathrm{~g}$ for $5 \mathrm{~min}$, and then the supernatant was analyzed by HPLC/AAS.

The mouse liver was homogenized in a $4 \times$ tissue volume of $50 \mathrm{mM} \mathrm{KPi}(\mathrm{pH} 7.4)$, followed by centrifugation at $9000 \mathrm{~g}$ for $10 \mathrm{~min}$. The protein concentration of the $9000 \mathrm{~g}$ supernatant was determined by a Protein Assay BCA Kit (Nacalai, Kyoto, Japan). ( $\mathrm{MeHg})_{2} \mathrm{~S}(100 \mu \mathrm{M})$ was incubated in the liver supernatant centrifuged at $9000 \mathrm{~g}(2 \mathrm{mg} /$ $\mathrm{mL}$ ) or in $50 \mathrm{mM} \mathrm{KPi}\left(\mathrm{pH} \mathrm{7.5)}\right.$ for $0-7$ days at $37^{\circ} \mathrm{C}$, and liquid-liquid extraction was performed to determine the organic and/or inorganic Hg content by AAS (MA-3000; Nihon Instruments, Osaka, Japan). To determine the contribution of protein during the degradation of $(\mathrm{MeHg})_{2} \mathrm{~S}$ in the mouse liver $9000 \mathrm{~g}$ supernatant, the $9000 \mathrm{~g}$ supernatant $(400 \mu \mathrm{g})$ was incubated at $25^{\circ} \mathrm{C}$ or $95^{\circ} \mathrm{C}$ for $15 \mathrm{~min}$, followed by cooling on ice for $5 \mathrm{~min}$. $(\mathrm{MeHg})_{2} \mathrm{~S}$ (at a final concentration of $100 \mu \mathrm{M}$ ) was incubated in the nonheated or heated supernatant $\left(2 \mathrm{mg} / \mathrm{mL}\right.$ ) at $37^{\circ} \mathrm{C}$ for $24 \mathrm{~h}$. The low-molecular-weight fraction of $4 \mathrm{mg} / \mathrm{mL}$ of the liver $9000 \mathrm{~g}$ supernatant was fractionated using Amicon Ultra (ultracel $3 \mathrm{~K}$ ). ( $\mathrm{MeHg})_{2} \mathrm{~S}$ (at a final concentration of $100 \mu \mathrm{M}$ ) was incubated in the low-molecularweight fraction $\left(2 \mathrm{mg} / \mathrm{mL}\right.$ ) at $37^{\circ} \mathrm{C}$ for $24 \mathrm{~h}$. After incubation, formic acid (at a final concentration of $1 \%$ ) was added to the mixture, which was centrifuged at $14000 \mathrm{~g}$ for $5 \mathrm{~min}$. The supernatant was analyzed by HPLC/AAS.

Analysis of $\mathrm{MeHg}$ and $(\mathrm{MeHg})_{2} \mathrm{~S}$ by HPLC/AAS. $\mathrm{MeHg}$ and $(\mathrm{MeHg})_{2} \mathrm{~S}$ in the fractions were detected with retention times of approximately 3-5 min and 10-15 min, respectively, as previously described ${ }^{16,19}$. Briefly, samples were subjected to HPLC equipped with a Zorbax Eclipse XDB- $\mathrm{C}_{18}$ column $(50 \mathrm{~mm}$ long, $2.1 \mathrm{~mm}$ i.d., $5 \mu \mathrm{m}$ particle size; Agilent Technologies, Santa Clara, CA, USA). The mobile phase was $10 \%$ methanol- $0.1 \%$ formic acid (the flow rate was $0.5 \mathrm{~mL} / \mathrm{min}$ ), and the mercury concentrations in the eluate fractions were determined using a direct thermal decomposition mercury analyzer with an AAS detector (MA-3000). A mercury standard solution diluted in $100 \mathrm{mg} / \mathrm{L}$ cysteine solution was used to prepare a standard curve for AAS.

Detection of organic and inorganic $\mathrm{Hg}$ from $(\mathrm{MeHg})_{2} \mathrm{~S} . \quad(\mathrm{MeHg})_{2} \mathrm{~S}(100 \mu \mathrm{M})$ in $50 \mathrm{mM} \mathrm{KPi}(\mathrm{pH} 7.5)$ was incubated for $0-7$ days at $37^{\circ} \mathrm{C}$. An aliquot of the sample $(500 \mu \mathrm{L})$ was mixed with $100 \mu \mathrm{L}$ of $6 \mathrm{~N} \mathrm{HCl}$ and $600 \mu \mathrm{L}$ of benzene and stirred for $5 \mathrm{~min}$. After centrifugation $(13000 \mathrm{~g}, 5 \mathrm{~min}$ ) of the mixture, a benzene layer was collected, and then $600 \mu \mathrm{L}$ of benzene was added to the water layer. The extraction process was repeated four times. The Hg content was measured by AAS in the collected benzene layer and water layer, which was neutralized by the addition of $1.71 \mathrm{~N} \mathrm{NaOH}(500 \mu \mathrm{L})$.

Determination of insoluble mercury. $\quad(\mathrm{MeHg})_{2} \mathrm{~S}(10 \mathrm{mM})$ in $50 \mathrm{mM} \mathrm{KPi}(\mathrm{pH} 7.5)$ was stirred for 7 days at room temperature and then filtered. The residue was washed with $20 \mathrm{~mL}$ of pure water and $20 \mathrm{~mL}$ of methanol, dried using an aspirator, suspended in pure water and benzene and stirred for $5 \mathrm{~min}$. After centrifugation, $\mathrm{Hg}$ in the benzene layer was determined by AAS. The process was repeated until the $\mathrm{Hg}$ content in the benzene layer was less than $10 \mathrm{ng}$. The solvents were then removed, and the residue was washed with $10 \mathrm{~mL}$ of methanol three times and dried by an aspirator. To determine the crystal structure of the compound, powder XRD experiments (Rigaku Ultima-III, Rigaku, Tokyo, Japan; $\mathrm{Cu} \mathrm{Ka}, 40 \mathrm{kV}-30 \mathrm{~mA}, \theta / 2 \theta$ scanning, angular step $0.02^{\circ}, 3 \mathrm{~s}$ accumulation per step) were carried out.

Detection of volatile $\mathrm{Hg}$ by GC/MS. Volatile Hg compounds were collected by XAD-4, and then the absorbed chemicals were extracted using $1 \mathrm{~mL}$ of acetone and analyzed by GC/MS. The samples were separated by an InertCap $5 \mathrm{MS} / \mathrm{Sil}$ column ( $30 \mathrm{~m}$ long, $0.25 \mathrm{~mm}$ i.d., $0.25 \mu \mathrm{m}$ df; GL Sciences, Tokyo, Japan) that was maintained at $40^{\circ} \mathrm{C}$, with $\mathrm{He}\left(\geq 99.99995 \%\right.$ purity) used as the carrier gas. The temperature was set as follows: $40^{\circ} \mathrm{C}$ 
for $5 \mathrm{~min}$; a linear increase to $150^{\circ} \mathrm{C}\left(6^{\circ} \mathrm{C} / \mathrm{min}\right)$; hold at $150{ }^{\circ} \mathrm{C}$ for $5 \mathrm{~min}$; and an increase to $200{ }^{\circ} \mathrm{C}$ over $1 \mathrm{~min}$. The eluted compounds were then transferred to the EI source $(70 \mathrm{eV})$ of the system, and the control and analyses were performed using GCMSsolution ver 4.44 (Shimadzu) ${ }^{\star}$. ${ }^{*}$ Unfortunately, we were not able to determine $\mathrm{DMeHg}$ quantitatively using GC/MS because of its high vapor pressure.

Detection of $\mathrm{CH}_{4}$ by GC/MS. DMeHg $(4 \mathrm{mM})$ or $\mathrm{MeHgCl}(4 \mathrm{mM})$ in $0.5 \mathrm{~N} \mathrm{HCl}-50 \%$ methanol was incubated for $3 \mathrm{~h}$ or 4 days at room temperature in a glass vial, and then the sample was analyzed by GC/MS. Gas in the headspace of the sample tube was injected using a gas-tight syringe and separated by TC-BOND Q (30 m long, $0.32 \mathrm{~mm}$ i.d., $10 \mu \mathrm{m}$ df; GL Sciences) with a PLOT column particle trap ( $2.5 \mathrm{~m}$ long, $0.25 \mathrm{~mm}$ i.d.; GL Sciences). The temperature was set as follows: $35^{\circ} \mathrm{C}$ for $5 \mathrm{~min}$; a linear increase to $220^{\circ} \mathrm{C}\left(12{ }^{\circ} \mathrm{C} / \mathrm{min}\right)$; and hold at $220^{\circ} \mathrm{C}$ for $5 \mathrm{~min}$. The eluted compounds were then transferred to the EI source of the system and analyzed using GCMSsolution (Shimadzu) as described above.

Detection of MeHg by El-MS. DMeHg ( $4 \mathrm{mM})$ in $0.5 \mathrm{~N} \mathrm{HCl}-50 \%$ methanol was incubated for 4 days at room temperature in a glass vial. A $10 \mu \mathrm{L}$ aliquot of the sample was subjected to EI-MS, and the control and treatment analyses were performed using GCMSsolution and direct-injection mode.

Statistical analysis. Each experiment was repeated at least three times, and representative data are shown. All statistical analyses were performed using GraphPad Prism version 6.0 software (GraphPad, San Diego, CA, USA). Statistical significance was assessed by the differences in a population mean test, followed by the Welch test, or one-way ANOVA followed by a Tukey's multiple comparisons test with $P<0.05$ considered significant.

\section{Data availability}

All data generated or analyzed during this study are included in this published article and its Supplementary Information files.

Received: 23 April 2021; Accepted: 13 July 2021

Published online: 02 September 2021

\section{References}

1. Hintelmann, H. Organomercurials. Their formation and pathways in the environment. Met. Ions Life Sci. 7, 365-401. https://doi. org/10.1039/BK9781847551771-00365 (2010).

2. Grandjean, P., Satoh, H., Murata, K. \& Eto, K. Adverse effects of methylmercury: Environmental health research implications. Environ. Health Perspect. 118, 1137-1145. https://doi.org/10.1289/ehp.0901757 (2010).

3. Kanda, H., Shinkai, Y. \& Kumagai, Y. S-mercuration of cellular proteins by methylmercury and its toxicological implications. J. Toxicol. Sci. 39, 687-700 (2014).

4. Simpson, R. B. Association constants of methylmercury with sulfhydryl and other bases. J. Am. Chem. Soc. 83, 4711-5000. https:// doi.org/10.1021/ja01484a005 (1961).

5. Toyama, T. et al. Cytoprotective role of Nrf2/Keap1 system in methylmercury toxicity. Biochem. Biophys. Res. Commun. 363, 645-650. https://doi.org/10.1016/j.bbrc.2007.09.017 (2007).

6. Unoki, T. et al. Methylmercury, an environmental electrophile capable of activation and disruption of the Akt/CREB/Bcl-2 signal transduction pathway in SH-SY5Y cells. Sci. Rep. 6, 28944. https://doi.org/10.1038/srep28944 (2016).

7. Joshi, D., Mittal, D. K., Shukla, S. \& Srivastav, A. K. Therapeutic potential of N-acetyl cysteine with antioxidants (Zn and Se) supplementation against dimethylmercury toxicity in male albino rats. Exp. Toxicol. Pathol. 64, 103-108. https://doi.org/10.1016/j. etp.2010.07.001 (2012).

8. Nierenberg, D. W. et al. Delayed cerebellar disease and death after accidental exposure to dimethylmercury. N. Engl. J. Med. 338, 1672-1676. https://doi.org/10.1056/NEJM199806043382305 (1998).

9. Ballatori, N. Transport of toxic metals by molecular mimicry. Environ. Health Perspect. 110(Suppl 5), 689-694 (2002).

10. Itoh, K. et al. Keap1 regulates both cytoplasmic-nuclear shuttling and degradation of Nrf2 in response to electrophiles. Genes Cells 8, 379-391 (2003).

11. Mahaffey, C. M. et al. Multidrug-resistant protein-3 gene regulation by the transcription factor Nrf2 in human bronchial epithelial and non-small-cell lung carcinoma. Free Radic. Biol. Med. 46, 1650-1657. https://doi.org/10.1016/j.freeradbiomed.2009.03.023 (2009).

12. Ketterer, B., Coles, B. \& Meyer, D. J. The role of glutathione in detoxication. Environ. Health Perspect. 49, 59-69. https://doi.org/ 10.1289/ehp.834959 (1983).

13. Rabenstein, D. L., Reid, R. S. \& Isab, A. A. H nmr study of the effectiveness of various thiols for removal of methylmercury from hemolyzed erythrocytes. J. Inorg. Biochem. 18, 241-251 (1983).

14. Rabenstein, D. L., Arnold, A. P. \& Guy, R. D. 1H-NMR study of the removal of methylmercury from intact erythrocytes by sulfhydryl compounds. J. Inorg. Biochem. 28, 279-287 (1986).

15. Yoshida, E., Abiko, Y. \& Kumagai, Y. Glutathione adduct of methylmercury activates the Keap1-Nrf2 pathway in SH-SY5Y cells. Chem. Res. Toxicol. 27, 1780-1786. https://doi.org/10.1021/tx5002332 (2014).

16. Yoshida, E. et al. Detoxification of methylmercury by hydrogen sulfide-producing enzyme in Mammalian cells. Chem. Res. Toxicol. 24, 1633-1635. https://doi.org/10.1021/tx200394g (2011).

17. Ida, T. et al. Reactive cysteine persulfides and S-polythiolation regulate oxidative stress and redox signaling. Proc. Natl. Acad. Sci. USA 111, 7606-7611. https://doi.org/10.1073/pnas.1321232111 (2014).

18. Ono, K. et al. Redox chemistry and chemical biology of H2S, hydropersulfides, and derived species: Implications of their possible biological activity and utility. Free Radic. Biol. Med. 77, 82-94. https://doi.org/10.1016/j.freeradbiomed.2014.09.007 (2014).

19. Abiko, Y. et al. Involvement of reactive persulfides in biological bismethylmercury sulfide formation. Chem. Res. Toxicol. 28, 1301-1306. https://doi.org/10.1021/acs.chemrestox.5b00101 (2015).

20. Tomasova, L., Konopelski, P. \& Ufnal, L. Gut bacteria and hydrogen sulfide: The new old players in circulatory system homeostasis. Molecules 21, 1558. https://doi.org/10.3390/molecules21111558 (2016).

21. Blachier, F., Beaumont, M. \& Kim, E. Cysteine-derived hydrogen sulfide and gut health: A matter of endogenous or bacterial origin. Curr. Opin. Clin. Nutr. Metab. Care 22, 68-75. https://doi.org/10.1097/MCO.0000000000000526 (2019). 
22. Barton, L. L., Ritz, N. L., Fauque, G. D. \& Lin, H. C. Sulfur cycling and the intestinal microbiome. Dig. Dis. Sci. 62, 2241-2257. https://doi.org/10.1007/s10620-017-4689-5 (2017).

23. Rodic, D., Spasojevic, V., Bajorek, A. \& Onnerud, P. Similarity of structure properties of $\operatorname{Hg}_{1-\mathrm{x}} \mathrm{Mn}_{\mathrm{x}} \mathrm{S}$ and $\mathrm{Cd}_{1-\mathrm{x}} \mathrm{Mn}_{\mathrm{x}} \mathrm{S}(\mathrm{structure}$ properties of HgMnS and CdMnS). J. Magn. Magn. Mater. 152, 159-164. https://doi.org/10.1016/0304-8853(95)00435-1 (1996).

24. Penak, V., McCarthy, G. \& Bayliss, P. ICDD Grand-in-Aid (ICDD, North Dakota State Univ., Fargo, North Dakota, USA, 1991).

25. Fagerstrom, T. \& Jernelov, A. Some aspects of the quantitative ecology of mercury. Water Res. 6, 1193-1202. https://doi.org/10. 1016/0043-1354(72)90019-X (1972).

26. Bytautas, L. Stability of dimethylmercury and related mercury-containing compounds with respect to selected chemical species found in aqueous environment. Croat. Chem. Acta. 86, 453-462. https://doi.org/10.5562/cca2314 (2013).

27. Craig, P. J. \& Bartlett, P. D. Role of hydrogen-sulfide in environmental transport of mercury. Nature 275, 635-637. https://doi.org/ $10.1038 / 275635 \mathrm{a} 0$ (1978).

28. Jonsson, S., Mazrui, N. M. \& Mason, R. P. Dimethylmercury formation mediated by inorganic and organic reduced sulfur surfaces. Sci. Rep. 6, 27958. https://doi.org/10.1038/srep27958 (2016)

29. Kanzler, C. R. et al. Emerging investigator series: Methylmercury speciation and dimethylmercury production in sulfidic solutions. Environ. Sci. Process. Impacts 20, 584-594. https://doi.org/10.1039/c7em00533d (2018).

30. Abiko, Y., Katayama, Y., Akiyama, M. \& Kumagai, Y. Lipophilic compounds in garlic decrease the toxicity of methylmercury by forming sulfur adducts. Food Chem. Toxicol. 150, 112061. https://doi.org/10.1016/j.fct.2021.112061 (2021).

31. Francoleon, N. E., Carrington, S. J. \& Fukuto, J. M. The reaction of H(2)S with oxidized thiols: generation of persulfides and implications to H(2)S biology. Arch. Biochem. Biophys. 516, 146-153. https://doi.org/10.1016/j.abb.2011.09.015 (2011).

32. Berlin, M., Zalups, K. R. \& Fowler, A. B. Mercury in Handbook on the Toxicology of Metals (eds G. Nordberg, B. Fowler, \& M. Nordberg) Ch. 46, 1013-1075 https://doi.org/10.1016/b978-0-444-59453-2.00046-9 (Academic Press, 2015).

33. Seki, N. et al. Adverse effects of methylmercury on gut bacteria and accelerated accumulation of mercury in organs due to disruption of gut microbiota. J. Toxicol. Sci. 46, 91-97. https://doi.org/10.2131/jts.46.91 (2021).

34. Horai, S. et al. Establishment of a primary hepatocyte culture from the small Indian mongoose (Herpestes auropunctatus) and distribution of mercury in liver tissue. Ecotoxicology 23, 1681-1689. https://doi.org/10.1007/s10646-014-1307-6 (2014).

\section{Acknowledgements}

This work was supported in part by Grants-in-Aid for Scientific Research (18H05293 to Y. Kumagai) from the Ministry of Education, Culture, Sports, Science and Technology of Japan and by Research funding to Y.A. from the Urakami Foundation for Food and Food Culture Promotion. We thank Masahiro Akiyama, who kept and cared for the mice until the experiments.

\section{Author contributions}

Y.A. performed the HPLC/AAS and GC/MS analyses, discussed the results and contributed to writing the manuscript. Y.Ka. performed the AAS analysis following liquid-liquid extraction and GC/MS. K.S. and W.Z. contributed to the XRD analysis. S.H. captured the mongoose and prepared the samples. Y.Ku. supervised and coordinated the research.

\section{Competing interests}

The authors declare no competing interests.

\section{Additional information}

Supplementary Information The online version contains supplementary material available at https://doi.org/ 10.1038/s41598-021-96579-y.

Correspondence and requests for materials should be addressed to Y.K.

Reprints and permissions information is available at www.nature.com/reprints.

Publisher's note Springer Nature remains neutral with regard to jurisdictional claims in published maps and institutional affiliations.

\footnotetext{
(c) (i) Open Access This article is licensed under a Creative Commons Attribution 4.0 International License, which permits use, sharing, adaptation, distribution and reproduction in any medium or format, as long as you give appropriate credit to the original author(s) and the source, provide a link to the Creative Commons licence, and indicate if changes were made. The images or other third party material in this article are included in the article's Creative Commons licence, unless indicated otherwise in a credit line to the material. If material is not included in the article's Creative Commons licence and your intended use is not permitted by statutory regulation or exceeds the permitted use, you will need to obtain permission directly from the copyright holder. To view a copy of this licence, visit http://creativecommons.org/licenses/by/4.0/.
}

(C) The Author(s) 2021 